\title{
ASSESSMENT OF TREATMENT OUTCOME IN TUBERCULOSIS PATIENTS APPROACHING A TERTIARY CARE TEACHING HOSPITAL
}

\author{
RIYA JAISON ${ }^{1}$, SUJA ABRAHAM ${ }^{1}$, MARY SRUTHY JOHNY ${ }^{1}$, VASANT PK ${ }^{2}$, LAKSHMI R ${ }^{1 *}$ \\ ${ }^{1}$ Department of Pharmacy Practice, Amrita School of Pharmacy, Amrita Vishwa Vidyapeetham, Kochi - 682 041, Kerala, India. ${ }^{2}$ Department \\ of Internal Medicine, Amrita Institute of Medical Sciences and Research Centre, Kochi - 682 041, Kerala, India. \\ Email: lakshmir@aims.amrita.edu \\ Received: 29 January 2017, Revised and Accepted: 04 April 2018
}

ABSTRACT

Objectives: The main objectives of the study were to determine the treatment outcome of tuberculosis (TB) patients in a tertiary care hospital, factors associated with the success of treatment, the adverse drug reactions (ADRs) associated with anti-tubercular drugs, and the causality and severity evaluation of ADRs.

Methods: It was a prospective study conducted for 10 months to evaluate the treatment outcome in TB patients in a tertiary care teaching hospital in Kerala, India. A total of 101 patients were studied as per the inclusion and exclusion criteria. Treatment outcome analyzed according to the WHO guidelines, causality and severity assessment was done by Naranjo and HARTWID-SIEGEL scale, respectively. A standardized data collection form was prepared, and necessary data were collected from patient's medical records.

Results: A total of 101 patients mostly in the age group of 30-50 years were male population dominates pulmonary TB (PTB) was seen in 57 (56.43\%) extra PTB in $44(43.57 \%)$ in which pleural effusion TB was common (34.09\%) other types were lymph node TB (15.74\%), spine TB, TB meningitis (9.09\% each), bone TB (6.481\%) treatment outcome found to be success in 85 (84\%) 10 (10\%)treatment completed 1 (1\%) died 4 were defaulters, 1 not evaluated, 82 developed ADR. On causality assessment it was possible and severity of moderate level.

Conclusion: By proper management and monitoring TB can be completely cured, and most of them have a favorable outcome with current treatment, and ADR can be managed by providing proper awareness of treatment modalities/disease.

Keywords: Tuberculosis, Mycobacterium, Treatment outcome.

(C) 2018 The Authors. Published by Innovare Academic Sciences Pvt Ltd. This is an open access article under the CC BY license (http://creativecommons. org/licenses/by/4. 0/) DOI: http://dx.doi.org/10.22159/ajpcr.2018.v11i5.25012

\section{INTRODUCTION}

Tuberculosis (TB) is a bacterial infection caused by Mycobacterium TB (M.TB) transmitted through the air [1]. It can spread through the lymph nodes and bloodstreams to any organ in the body. It is most often found in the lungs [2]. Most people who are exposed to TB never develop symptoms as bacteria live in an inactive form and become active when immune system weakens and infect the tissue of the infected organ. Hence, the two types are latent and active TB, the latter can be fatal if left untreated [3]. TB is caused by group of bacteria called M.TB complex they are M.TB (major causative organism), Mycobacterium africanum, Mycobacterium microti, and Mycobacterium canetti [4,5]. In droplet infection, the patient breathes in tubercle bacilli, it settles in lungs and begins to grow, and from there, it migrates to different organs [6]. TB in lungs or throat is infectious while in other parts are not usually [5,7]. TB can be classified based on anatomical site as pulmonary, extrapulmonary, miliary TB and on the previous history as new, previously treated, relapse, failure, default and based on drug resistance as mono, polydrug, multidrug, extensive drug, and rifampicin-resistant TB [8]. Diagnosis is done by tuberculin skin test.

Risk factors include person who has been recently infected with TB bacteria, persons with a medical condition that weakens the immune system.

Clinical features-bad cough that pasts 3 weeks or more, chest pain, hemoptysis, weakness, fatigue, weight loss, chills, fever, night sweats, etc.

Treatment of TB - the major goal is to cure, minimize the risk of death and disability and reduce transmission to other persons. The major hindrances to TB therapy are long duration of therapy, patients' low confidence, and potential adverse effects [9]. The first line drugs for treatment are isoniazid, rifampicin, pyrazinamide (PZA), ethambutol, rifabutin, and rifapentine while second-line drugs include streptomycin, cycloserine, capreomycin, p-aminosalicylic acid, levofloxacin, moxifloxacin, gatifloxacin, amikacin, and ethionamide $[10,11]$. Each treatment regimen consists of an initial 2-month treatment followed by a continuation phase of either 4 or 7 months, treatment completion and follow-up after the treatment. The treatment outcome is monitored to evaluate the efficacy and effectiveness of treatment according to the WHO [6]. International Union and Tubercular Lungs disease classifies the treatment outcome as successfully treated, treatment completed, failed, died, lost to follow-up, and not evaluated [12]. The standard treatment of TB consists of isoniazid, rifampicin, PZA, and ethambutol this regimen is effective but is associated with many adverse drug reactions (ADRs) [13-17].

Isoniazid-systemic or cutaneous hypersensitivity reactions, optic neuritis, toxic psychosis, generalized convulsions, symptomatic hepatitis.

Ethambutol-optic neuritis, visual acuity, color blindness, peripheral neuritis.

PZA-gastrointestinal intolerance, hypersensitivity reactions, arthralgia.

Rifampicin-gastrointestinal reactions, exfoliative dermatitis common in Human immunodeficiency virus positive TB patient, oliguria, dyspnoea and haemolytic anemia. 


\section{METHODS}

\section{Study design}

This was a prospective observational study, which was approved by the Research Committee of Amrita School of Pharmacy and by the Ethical Committee of AIMS.

\section{Study duration}

The study period was from November 2013 to June 2014.

\section{Study population}

The patients were taken from both the departments of pulmonary and general medicine of a tertiary care teaching hospital in Kerala during the period (November 2013-June 2014) and who satisfied the inclusion and exclusion criteria were included in the study.

\section{Inclusion criteria}

The following criteria were included in this study:

- Patients who were diagnosed with TB and on anti-tubercular drugs.

- Patients of all age group.

\section{Exclusion criteria}

The following criteria were excluded from the study:

- Patients diagnosed with acquired immunodeficiency syndrome.

- Patients with resistance to TB medication.

- Not willing to participate in the study.

\section{Data collection}

Patient data relevant to the study were collected by interviewing the patient and by examining the medical record using a standard data collection form. Causality of ADRs was assessed using Naranjo scale, and the severity assessment was done by modified HARTWIG and SIEGEL scale.

\section{Statistical analysis}

All the collected data were tabulated, analyzed and compared with data from other studies. Collected data were compiled using Microsoft Excel and presented in pie charts and bar diagrams. Calculation of mean and standard deviation was done using descriptive statistical methods and significance by paired t-test and the statistical software used was SPSS Version 20.

\section{RESULTS}

A total of 101 patients were included in this study during a period of 10 months. Most of the patients were in the age group of 30-50 and the mean age was found to be $44.98 \pm 17.005$ years (Fig. 1). Patients having pulmonary TB (PTB) was mainly in the age group of 41-50 years and of extra (PTB) (EPTB) was $51-60$ years with mean age $46.25 \pm 17.46$ years and $46.25 \pm 1677$ years, respectively. The number of male patients was $74(73.27 \%)$ and females were $27(26.73 \%)$, and the male to female ratio was 2.7:1. 57 had PTB, out of which $47(71.93 \%)$ were male and $16(28.07 \%)$ were female. 44 patients had EPTB, out of which 33 (75\%) were male and $11(25 \%)$ were female. Analysis of social history revealed that 27 (26.73\%) were smokers, 10 (9.9\%) were alcoholics, and 14 (13.86\%) were both (Table 1).

The sites of EPTB were studied, and the most common was pleural effusion 15 (34.09\%) (Fig. 2), and the TB patients were categorized based on TB treatment as new cases (81\%), relapse $(15 \%)$, and failure (4\%) (Table 2).

As per the WHO guidelines treatment outcome was categorized as a success, treatment completed, died, failed and lost to follow-up, and not evaluated. Failure cases were not found in this study (Table 3).

The time interval from onset of therapy and the detection of hepatotoxicity ranged from 15 to 60 days and from onset of hepatotoxicity to normalization of liver function test (LFT) was $15-45$ days, 13 patients had elevation in LFT without jaundice within 2-4 weeks of TB treatment almost 75\% had normalization within 2 weeks of cessation of treatment (Table 3). Out of 101, 82 patients of which 62 were male and 20 were female, had been presented with ADRs mostly seen in the age group above 40, and a total of 127 ADRs were reported. Most of the reactions were observed in the gastrointestinal tract (Fig. 3). Isoniazid, rifampicin, and PZA caused hepatotoxicity. PZA caused joint pain while peripheral and optic neuropathy was caused by isoniazid and ethambutol, respectively. The observed ADRs were managed by discontinuing the causative drug (rifampicin and ethambutol) or by withholding the specified drug (PZA) and continuing when symptoms resolved or by doing treatment modification or by addition of another TB drug (ofloxacin added to patients who had hepatotoxicity) and by taking conservative measures and continuing the treatment.

Causality assessment of ADRs was done using Naranjo algorithm, 50\% ADR were possible, $12 \%$ were probable, and $38 \%$ were definite, and

Table 1: Social history of patients

\begin{tabular}{lll}
\hline Social history & \multicolumn{2}{l}{ Number of patients } \\
\cline { 2 - 3 } & PTB (57) & EPTB (44) \\
\hline Smoking (27) & $20(35.08 \%)$ & $7(15.9 \%)$ \\
Alcoholism (10) & $4(7.01 \%)$ & $6(13.63 \%)$ \\
Smoking+alcohol (14) & $7(12.28 \%)$ & $7(15.9 \%)$ \\
\hline
\end{tabular}

Table 2: Category of TB based on treatment

\begin{tabular}{lll}
\hline Category & PTB (57)) & EPTB (44) \\
\hline New & $44(77.19 \%)$ & $38(86.36 \%)$ \\
Relapse & $10(17.54 \%)$ & $5(11.36 \%)$ \\
Failure & $3(5.26 \%)$ & $1(2.27 \%)$ \\
\hline
\end{tabular}

TB: Tuberculosis, PTB: Pulmonary tuberculosis, EPTB: Extra pulmonary tuberculosis

Table 3: TB treatment outcome

\begin{tabular}{llll}
\hline Treatment outcome & PTB (57) & EPTB (44) & Total (\%) \\
\hline Success & $47(82.45 \%)$ & $38(86.36 \%)$ & $85(84.15)$ \\
Completed & $5(8.77 \%)$ & $5(11.63 \%)$ & $10(9.90)$ \\
Died & $1(1.75 \%)$ & - & 1 \\
Lost to follow-up & $3(5.26 \%)$ & $1(2.27 \%)$ & $4(3.96)$ \\
Not evaluated & $1(1.75 \%)$ & - & $1(0.99)$ \\
Failed & - & - & - \\
\hline
\end{tabular}

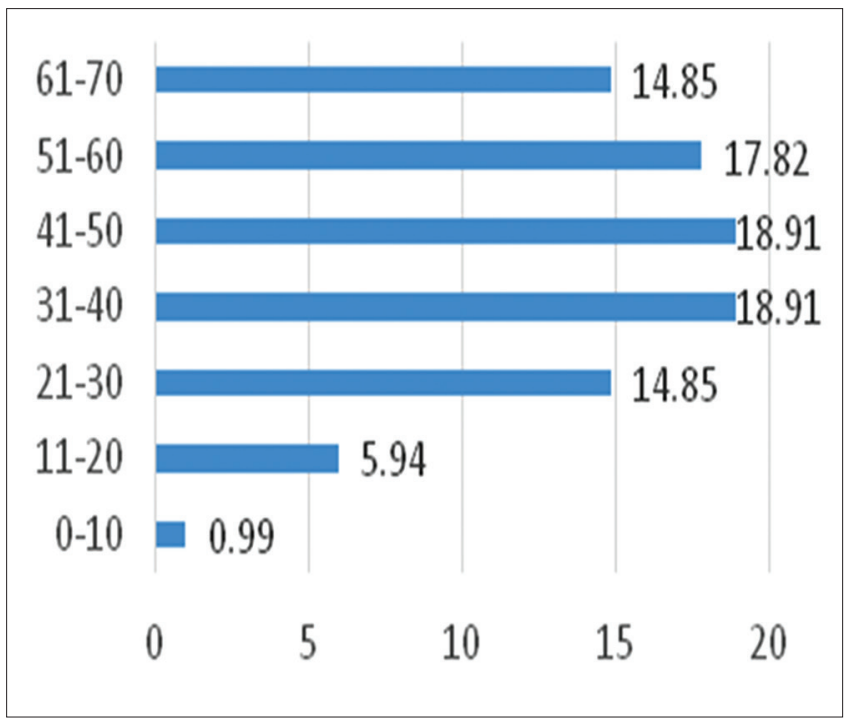

Fig. 1: Age distribution of patients 


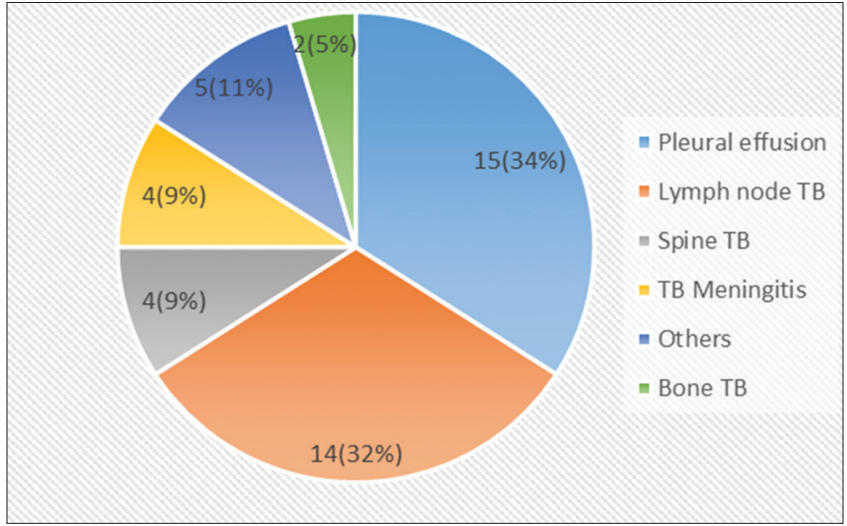

Fig. 2: Sites of extrapulmonary tuberculosis

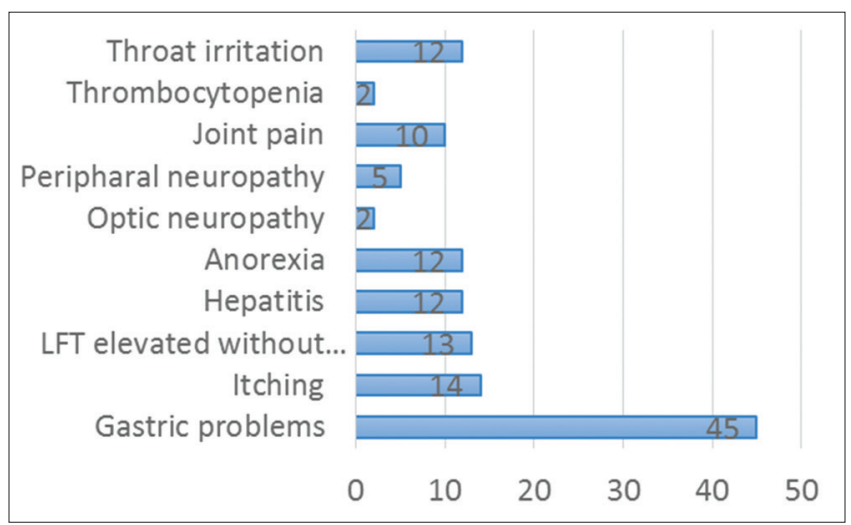

Fig. 3: Adverse drug reactions observed

there were no doubtful cases. According to this PZA was found to be the most common cause of ADR. Severity assessment of ADRs was done by Hartwig and Siegel scale in which it was found that 29.34\% ADRs were mild cases, $58.84 \%$ were moderate, and $15.92 \%$ were severe cases. The various factors affecting treatment outcome was studied and the results obtained where as follows on correlating age and treatment outcome, more success of treatment was found below 40 years, and there was no significant difference in age and treatment outcome $(\mathrm{p}=0.554)$. While assessing gender, females had more success rate with statistical significance. Favorable treatment outcome was seen in EPTB which was not of clinical significance $(p=0.796 \%)$. On analyzing the treatment outcome based on the category, the success rate was higher in PTB in the new category while in relapse all TB patients had favorable outcome and as failure cases could not be included as a favorable outcome, it was not included. Without not much statistical significance, favorable outcome was more in the group without ADR while assessing ADR and treatment outcome.

\section{DISCUSSION}

TB is the most prevalent infectious disease around the world, and its treatment involves anti-TB drugs. This study found out that TB was more common in males $(73.27 \%)$ than females (26.73\%) similar to Whitacare et al. study, that may be because of difference in hormone level cellular immunity, etc. [18]. In this study, PTB was more prevalent than EPTB, and according to 2013 TB status report also PTB was more prevalent [19]. In this present study finding, EPTB accounts for only $43.57 \%$, which was lower than the previous study conducted in India where EPTB accounted for 15-20\% [20,21]. In Hong Kong and USA genitourinary and skin TB and bones and joint TB, respectively, were more common EPTB while our study was similar to that from Turkey and India in which pleural effusion and lymph node TB was most common [22-25]. In this study, the treatment success rate was higher in female $92.6 \%$ than male $81.1 \%$ which was found to be statistically significant, but previous studies showed similar treatment success rate [26].

In our study, smokers had a higher percentage of PTB, and it was reported early that smoking, as well as alcoholism, increases the risk for $\mathrm{TB}[27,28]$. In the present study, failure and relapse cases were included and were $4 \%$ and $5 \%$, respectively, lower than previous studies, and treatment success rate of all TB cases was $84.1 \%$ which were lower than the result obtained in the study conducted by Shargie and Linditjorn (49\%) and the study conducted in India (70.8\%) [29-32]. The successful treatment depends on the susceptibility of bacterial strain to medication, mutations of the virulent strain, drug regimen its duration and adherence to medication [33]. The death rate in the present study $(0.99 \%)$ lower than previous studies, overall in our study $86.36 \%$ of EPTB had success treatment outcome, $11.63 \%$ had completed, and $2.27 \%$ lost to follow-up [34-36].

The study showed that out of 101 patients only 82 (127 number of ADR) developed at least one type of ADR with an incidence rate of $81.18 \%$, lower than previous studies and most of the side effects were due to first-line anti-TB drugs $[37,38]$. The most serious side effect was hepatitis and was highest with PZA and was more in female patients, two similar studies also stated the same [39]. In this study occurrence of ADR rises with age, mostly seen in the age group of 41-50 years, but previous studies shown no relation of side effects with age [40].

The most common side effect seen in our study was GI system related reactions, 57 patients had nausea, and vomiting and decreased appetite and the responsible drugs were PZA and rifampicin and are similar to previous studies [41]. In our study, it was necessary to modify treatment regimen in $13.8 \%$ due to ADRs. 14 patients had itching or mild rashes due to the use of PZA, rifampicin or isoniazid and this could be managed by antihistamines similar results reported in previous studies and two developed optic neuropathy due to ethambutol, and so which was after discontinued and patient was referred to ophthalmologist [42-45]. In our study, $25(30.48 \%)$ had elevated levels of bilirubin, aspartate transaminase, alkaline phosphatase, and alanine transaminase after treatment as noted in the previous studies [46]. Higher dose of isoniazid increases neuro toxicity in this study 5 patients experienced peripheral neuropathy with complaints of numbness tingling in hand and feet, insensitivity to touch to overcome pyridoxine $40 \mathrm{mg}$ was given [47]; in our study, PZA caused slight increase in plasma uric acid level in 7 patients but could be managed by simple analgesics, the present study was in agreement with the study of Koju et al., the two of the patients had thrombocytopenia due to rifampicin and is in agreement with study of Nagamaya et al. in japan [40,41]. In our present study, 12 elderly patients who took multiple medications had experienced throat irritation. ADR was considered to be the main reasons for morbidity, mortality, and hospital stay and eve death. Evaluation of causality of ADRs majority was found to be possible cases (50\%), probable cases $(12 \%)$, and definite cases $(38 \%)$ this were in variation with other studies PZA caused most of the ADR. Among the ADR's in our study, $54.84 \%$ were categorized mild (level 1 and 2), 29.24\% were moderate (level 3 and 4), and 15.92\% were severe (level 5 and 6 ) as per modified Hartwig and Siegel scale.

\section{CONCLUSION}

The present study aimed to assess the treatment outcome of TB patients since it can be completely cured and eradicated by proper management and monitoring and it revealed that favorable outcome could be achieved with regular use of medicine and timely follow-up. Significant LFT elevations were observed in 25\% cases and all ADR's were managed by either modification of treatment regimen or other conservative measures. Success was found to be not associated with variables such as age, type of TB, category on treatment, and ADR except gender. Even though we are paying much attention to prevention of this disease, it is necessary to provide awareness about the disease and treatment modalities to the public and to join hands to eradicate the disease from our country. 


\section{AUTHOR'S CONTRIBUTION}

Mary Sruthy Jhony did the data collection and analysis under the guidance of Suja Abraham and Vasant PK. Others are involved in manuscript preparation.

\section{CONFLICTS OF INTEREST}

None.

\section{REFERENCES}

1. Arvind A, Jain V, Saravanan P, Mohan CG. Uridine monophosphate kinase as potential target for tuberculosis: From target to lead identification. Interdiscip Sci 2013;5:296-311.

2. Kumar GS, Venugopal AK, Kashyap MK, Raju R, Marimuthu A, Palapetta SM, et al. Gene expression profiling of tuberculous meningitis co-infected with HIV. J Proteomics Bioinform 2012;5:235-44.

3. Shaji J, Shaikh M. Drug resistant tuberculosis: Recent approach in polymer based nanomedicine. Int J Pharm Pharm Sci 2016;8:1-6.

4. Obasanya J, Patrobas P, Gidado M,Clement A, Liman H,Tari A, et al. Modules for the Training of Health Facility Workers in TB Control. $3^{\text {rd }}$ ed. Zaria, Nigeria: Jodda Comm Press; 2007. p. 5-25.

5. Jensen PA, Lambert LA, Iademarco M, Ridzon R. Centres for disease control and prevention. Guidelines for preventing the transmission of mycobacterium tuberculosis in health care settings. MMWR Recomm Rep 2005;54:1-141.

6. Arvind A, Kumar V, Saravanan P, Mohan CG. Homology modeling, molecular dynamics and inhibitor binding study on MurD ligase of Mycobacterium tuberculosis. Interdiscip Sci Comput Life Sci 2012;4:223-38.

7. Friden TR, Sterling TR, Munsiff SS, Watt CJ, Dye C. Tuberculosis. Lancet 2003;362:887-99.

8. Surveillance Reports: Reported Tuberculosis in the United States 2005. Centers for Disease Control and Prevention Web Site.

9. Illahi RK, Pramestutie HR, Desyana MS. The use of counselling tool" Lung TB Care to increase patients knowledge level (A study in tuberculosis patients at Malang's primar healthcare centers). Int J Pharm Pharm Sci 2018;10:1-4.

10. Hartwig SC, Siegel J, Schneider PJ. Preventability and severity assessment in reporting adverse drug reactions. Am J Hosp Pharm 1992;49:2229-32.

11. Patra S, Lukhmana S, Tayler Smith K, Kannan AT, Satyanarayana S, Enarson DA, et al. Profile and treatment outcomes of elderly patients with tuberculosis in Delhi, India: Implications for their management. Trans R Soc Trop Med Hyg 2013;107:763-8.

12. IUTALD. International Union against Tuberculosis and Lung Disease (IUATLD). Management of Tuberculosis: A guide for Low-Income Countries. IUTALD; 2013.

13. American Thoracic Society, Centers for Disease Control and Prevention, and Infectious Diseases Society of America. Treatment of tuberculosis. MMWR 2003;52:1-77.

14. Bernard L, Stern R, Lew D, Hoffmeyer P. Serotonin syndrome after concomitant treatment with linezolid and citalopram. Clin Infect Dis 2003;36:1197.

15. Doster B, Murray FJ, Newman R, Woolpert SF. Ethambutol in the initial treatment of pulmonary tuberculosis. U.S. Public health service tuberculosis therapy trials. Am Rev Respir Dis 1973;107:177-90.

16. Dunkley EJ, Isbister GK, Sibbritt D, Dawson AH, Whyte IM. The hunter serotonin toxicity criteria: Simple and accurate diagnostic decision rules for serotonin toxicity. QJM 2003;96:635-42.

17. Halevy S, Shai A. Lichenoid drug eruptions. J Am Acad Dermatol 1993;29:249-55

18. Whitacare CC, Reingold SC, O'Looney PA. A gender gap in autoimmunity. Science 1999;283:1277-8.

19. Yang Z, Kong Y, Wilson F. Foxma manifestations and diagnosis of extra pulmonary Tuberculosis. Rev Mal Respir 1997;14:S72-87.

20. Sudre P, Hirschel BJ, Gatell JM, Schwander S, Vella S, Katlama C, et al. Tuberculosis among European patients with the acquired immune deficiency syndrome. The AIDS in Europe study group. Tuber Lung Dis 1996;77:322-8.

21. Stelianides S, Belmatoug N, Fantin B. Manifestations and diagnosis of extrapulmonary tuberculosis. Rev Mal Respir 1997;14 Suppl 5:S72-87.

22. Nissapatron V, Kuppuswamy I, Rohela M, Khairul A, Fong MY. Extra pulmonary tuberculosis in Penisular Malasya: Retrospective study of
195 cases. Southeast Asian J Trop Med Public Health 2004;35:123-35

23. Ormerold LP, Horsefield N. Frequency and type of reactivation anti TB drugs: Observation in routine treatment. Tubercule Lung Dis 1996;77:37-42.

24. Sharma SK, Mohan A. Extra pulmonary tuberculosis. Indian J Med Res 2004:120:316-53.

25. Ariyothaini N, Paka P, Akarasewi P. Ciggerate smoking and its relation to pulmonary tuberculosis in adults. Southeast Asian J Trop Med Public Health 2004;35:219-27.

26. Addington WW. Patient compliance: The most serious remaining problem in the control of tuberculosis in the United States. Chest 1979;76:741-3.

27. Lewis JG, Chamberlain DA. Alcohol consumption and smoking habits in male patients with pulmonary tuberculosis. Br J Prev Soc Med 1963;17:149-52.

28. Pulido F, Pena JM, Rubio R. Relapse of tuberculosis after treatment in HIV-infected patients. Arch Intern Med 1997;157:227-32.

29. Bhal S, Sarin R, Jaiswal A, Choudary A, Singala N, Mukherjee S. Revised national tuberculosis control programme; an urban experience. Indian J Tuberc 1998:45:207-10.

30. Shargie E, Linditjorn B. DOTS improves treatment outcomes and service coverage for tuberculosis in South Ethiopia: A retrospective trend analysis. BMC Public Health 2005;5:1471-7.

31. Ministry of Health and Family Welfare. Revised National tuberculosis control programme status report. New-Delhi, India: Central TB Division, Directorate General of Health Services, Ministry of Health and Family Welfare, Nirmala Bhavan; 2012. p. 7-17.

32. Chennaveerappa PK, Siddharam SM, Halesha BR, Vittal BG, Jayashree N. Treatment outcome of tuberculosis patients registered at dots centre in a teaching hospital, south India. Int J Biol Med Res 2011:2:487-9.

33. Mukesh M, Prathap MM, Sabitha M. Structural model of the alpha phosphoglucomutase: A promising target for the treatment of mycobacterium tuberculosis. Int J Pharm Pharm Sci 2013;5:107-14

34. Dholakia Y, Danani U, Desai C. Relapse Following directly observed treatment short course-a follow-up study. India J Tuberc 2000;47:233-6.

35. Fraser W, Balasubramanian R, Mohan A, Sharma SK. Extra pulmonary Tuberculosis: Management and Control. Indian J Tuber 2000;47:123-8.

36. Chakaya JM, Kibuga D, Ng'ang'a L, Githui WA, Mansoer JR, Gakiria G, et al. Tuberculosis retreatment outcomes within the public services in Nairobi, Kenya. East Afr Med J 2002;79:11-5.

37. Schaberg T, Rahban K, Lode H. Risk factors for side effects of isoniazid, Rifampicin and Pyrazinamide in patients hospitalized for pulmonary tuberculosis. Eur Respir 1996:9:2026-30.

38. Durand F, Jebark G, Pessayer D, Fournier N, Berand J, Hepatotoxicity of anti-tuberculosis drugs: Rational for monitoring liver status. Drug safety 1996;15:394-405

39. Dossing M, Wilcke TR, Askgaard DS, Nyboo B. Liver injury during. An 11-year study. Tuber Lung Dis 1996;77:31.

40. Singh J, Grag PK, Tandon RK. Hepatotoxicity due to anti tuberculosis therapy. Clinical profile and reintroduction of therapy. J Clin Gastroentrol 1996;22:211-4.

41. Sharma SK, Balamurugan A, Saha PK, Pande RM, Mehra NK. Evaluation of clinical and immunogenetic risk factors for the development of hepatotoxicity during anti-tuberculosis treatment. Am J Respir Crit Care Med 2002;166:916-9.

42. Koju D, Rao BS, Shrestha B, Shakya R, Makaju R. Occurance of sideeffects in urban nepalese population under DOTS Treatment, 200. Kathmandu Univ J Sci Eng Technol 2005;1:166-72.

43. Nagamaya N, Shisshido Y, Masunda K, Baba M, Tamura A, Nagai H, et al. Leukopenia due to anti-tuberculosis chemotherapy including rifampicin and isoniazid. Kekkaru 2004;79:341-8

44. Tak DK, Acharya LD. Safety evaluation of Ant tubercular therapy in India. J Clin Diagn Res 2009;3:1395-401.

45. Romanilos T, Casagran A, Barbeta E, Diestre J, Grau J, Marquillas E, et al. Pulmonary Tuberculosis: Effectiveness and tolerance of a 6-month treatment schedule using four drugs[Article in Spanish]. Rev Clin Esp 1990; $186: 116-8$

46. Getahun B, Ameni G, Biadgiligo S, Medhin G. Mortality and other associated risk factors in a cohort of tuberculosis patient treated under DOTS programme in Addis Ababa, Ethiopia. BMC Infect Dis 2011;11:127-34

47. Bernard N, Margret N. Factors associated with default from treatment among tuberculosis patient in Nairobi province, Kenya: A case control study. BMC Public Health 2011:11:696. 